\title{
Research of the morphological types of urban blocks in the old city of Nanjing
}

\author{
Haiqian Liu \\ School of Architecture, Southeast University. Nanjing. China \\ E-mail: liuhaiqian@126.com
}

\begin{abstract}
Research The block is one of the basic elements of urban space and its morphology is always changing due to the accumulation and substitution of constructions in different times. This article has taken the old city of Nanjing as an example to study the characteristics of blocks in old urban areas in China, where top-down plans and practical constructions remained conflicted in the long history of development. Extensive studies of relevant literature, quantitative researches and graphic analyses have been adopted to meet the research aims. This research has produced a number of key findings: at the scale of the whole city, the grid of streets tend to deviate from the boundaries of morphological homogeneous districts or, urban landscape units; blocks in the old city of Nanjing usually contain all or part of several different urban landscape units, which can be divided according to construction times and land-use types; the morphological difference of blocks can be presented by the different urban landscape units contained and the configuration pattern, so in this way the classification system of blocks has been discussed; some regularity has also been concluded regarding the transformation of block morphology.
\end{abstract}

Keywords: Nanjing, old city, plan unit, urban block, morphology

\section{Introduction}

This paper aims to investigate the features of blocks in the old city of Nanjing, which is on the base of urban morphology theories. Within urban morphology, a common feature in the definition of built form is the hierarchical structure of elements and the fundamental elements of built form include streets, plots and buildings. (Karl, 2013) Conzen, Caniggia and Maffei, Castex and Panerai are the representative scholars who have developed the concept of the compositional hierarchy within the typological approaches to urban morphology. They have identified elements of different levels in the hierarchy from different perspectives, but the position of urban block remains ambiguous.

As an urban morphologist in the field of geography, M. R. G. Conzen established some historico-geographical methods to describe and interpret built form, which are very important to the morphological research on urban blocks in this paper. Conzen proposed the idea of "form complexes" which includes ground plan, land utilization and building form as three components of the morphological character of an urban area. (Conzen, 1960) He established a hierarchy of morphological divisions to show unitary areas of the three basic form components, among which the ground plan generally determines the major units of the hierarchy, or to say plan units. And the identification of the building, plot and street was proposed by Conzen as the principal elements of the "plan unit". Meta Berghauser Pont and Per Haupt have discussed the relationship between plan units and blocks in a city, however, there is some incompatible 
when adopting that theory to analyze Chinese cities.

The form of a city could be observed, analyzed and described at different scale levels. Generally speaking, researches on urban morphology in China started very late in the 1980s and since then most of them have focused on the scale of a region or a city as a whole. There are some researches on mediate or micro scope discussing problems in ancient towns, but only few about current situation in urban area. Liang Jiang and Sun Hui discussed the transformation process of city form, especially of street and plot patterns, in central urban area, which is very helpful for us to understand the form of city blocks in China. However, the phenomenon of juxtaposition of different patterns was not discussed in depth.

This paper studies on the old city of Nanjing, namely, the area within the city wall constructed in Ming Dynasty, because the area with its rich historical accumulation is a perfect example of old urban areas in China. A variety of literary and cartographical sources, such as "Nanjing chenghsi guihua shi" (Urban Planning History of Nanjing) and "Jianguo yilai Nanjing chengshi kuozhan yanjiu" (Urban Growth in Nanjing since 1949), provide important information on the city development.

\section{Methodology}

To study the morphological types of blocks, this paper takes urban landscape units as a reference. An urban landscape could be interpreted as a mosaic of urban landscape units, which is the product of the combination of plan units, land use units and building form units according to Conzen's idea of "form complexes". Those units divide the city into many areas with homogeneous forms which could be explicitly recognized. Therefore, the principle and method to delimit the urban landscape units has firstly been established. Then the landscape units in the old city of Nanjing has been identified and mapped on the base of the geological information collected, including the construction periods and land use types of different areas. After that, the morphology of blocks has been studied on the scale of "superblock" divided by main streets, according to the urban landscape units contained. This research has focused on the situation of China, morphological characters of blocks, such as the relationship between the grid of blocks and the delimitation of urban landscape units has also been compared with existing theories in the western world.

\section{City development and morphological periods}

The capital city of many feudal dynasties in Chinese history was in the area of Nanjing and the built-up area scope kept changing due to the regime changes. The history of Nanjing City could date back to 472 B.C., when the king of Yue State built a City called "Yue" in the area of today's Nanjing. In 229 A.C., the king of Eastern Wu moved the kingdom's capital to the area of Nanjing and named it "Jianye". The city of Jianye was divided into two parts and the northern part was named "Jiankang" in Western Jin. Then in 317 A.C., "Jiankang" became the capital of Eastern Jin. After that, the Southern Dynasties (420-589), namely, Song Dynasty, Qi Dynasty, Liang Dynasty and Chen Dynasty, all established their capital in Jiankang one after another. After Chen Dynasty was defeated by Sui Dynasty, there had not been a capital in the area of Nanjing until the king of Southern Tang moved the capital to "Jiangning Fu" in 961 A.C. In different periods before Ming Dynasty, the city of Nanjing had kept mutative in terms of the boundary and the city structure.

It was in Ming Dynasty that the fundamental framework of the old city of Nanjing was established. Nanjing for the first time became the capital of the whole country in 1368 A.C. It was the only quadruply-walled capital in history, with four layers: a palace city, an imperial city, a capital city and an outer city. (Lei, 2016) The capital city was encircled by a city wall built in Ming Dynasty, which has been preserved in a great measure. The city continued the layout of Ming Dynasty and the constructions kept the traditional technique and pattern before 1864, when Taiping rebellion was suppressed by Qing government. After 1864, the introduction 
of modern civilization began to bring about changes to the city form and constructions. In the year of 1927, the Nationalist Party installed the Nationalist government in Nanjing and then the city experienced comparatively stable development mainly led by the Capital Plan in the following decade, until the Second SinoJapanese War broke out in 1937.

After successive warfare from 1937 to 1949 , the People's Republic of China was founded. Nanjing experienced a period of rehabilitation in which the old city was getting more replete with massive constructions on industrial buildings, institutions and government buildings. In this early socialist period, a kind of enclosed self-reliant compound called "Danwei" largely leaded the new constructions of the country. The Third Plenary Session of the 11th Central Committee held in 1978 proposed policies of reform and opening up. As a result, the economy system of China began to transit from planned economy to market economy. Moreover, a constitutional amendment in 1988 made the usufruct right of land a kind of property right and can be transferred, leased or mortgaged. (Food and Agriculture Organization of the United Nations, 2004) This policy actually came into force in Nanjing after 1992 when the "Notice on the relevant matters concerning the compensated use of state-owned land" was issued by the city government. (Yi, 2016) That means the replacement and new construction in the old city could be realized in larger piece of land with more regular shapes by a payment. Therefore, real estate development and renovation of the old city began to flourish in the 1990s.

Morphological periods, as Conzen proposed, refer to the periods during which large numbers of similar forms are reproduced. All the three components of "form complexes", ground plan, building form, and land utilization, derive their character from the historical and cultural context at the time of their creation and adaptation. (Whitehand, 2009) Ground plan is the form complex most resistant to change over time and thus becomes the most complete record of the urban form of different morphological periods. Therefore, the distinctiveness of morphological periods provides a basis for the plan units to be divided. Liang Jiang and Sun Hui divided the city centers in China into four patterns: traditional pattern in feudal period, colonial pattern in early modern period, planned-economy pattern and new pattern in modern period. (Jiang and Hui, 2007) Such a division could roughly summarize the types of morphological patterns in Chinese cities, but a more detailed periodization is needed for urban landscape units to be delimited in the particular city of Nanjing. Important turning points in history which greatly influenced the city landscape are picked as the border of the six morphological periods:

Traditional period: before 1864

Early modern period: $1864-1927$

Nationalist Government period: 1927-1949

Planned-economy period: 1949-1978

Early reform period: 1978-1992

Market-economy period: 1992-the present

\section{Urban landscape units in the old city of Nanjing}

As mentioned above, there is a hierarchy of urban landscape units according to Conzen's researches. The ground plan generally determines the major units while land utilization and building form are respectively the second- and third-order standard for subdivisions within form units. To reveal the morphological characters of blocks, this paper mainly investigates the relationship between blocks and the urban landscape units defined by the combination of plan units and land utilization units, because these two components determine the fundamental differences between form units at a mediate scale. The smallestscale units generally determined by the form of buildings are not discussed in this paper.

The ground plan of an urban area is characterized not only by the time when the area was formed but also by the time when important reconstruction projects were conducted. As for the core areas of a city, the pattern of the ground plan usually reflects some characters of ancient times when the area was formed, even though the buildings may have been replaced. That is because urban development usually 
tends to take use of existing streets with some modifications in certain parts and building constructions are at many times limited by the existing streets and plots. However, the adaptations of a certain area could sometimes make it completely different from the original one, especially in Chinese cities where the land-use system was subverted in the 1980s and the street and plot patterns of many areas were greatly changed. The periods in which different urban areas were formed and adapted have been taken into consideration. On the one hand, the urban expansion of Nanjing City has been examined and then the built-up areas in each morphological period have been mapped. On the other hand, the time information of major constructions for current blocks has been gathered and separated into five morphological periods. The mapping of areas constructed and adapted in each morphological period has been compared with built-up areas in different periods. (Figure 1) It has been shown that, before 1864, the urban development was mainly constrained in the south of the city. After the port in Xiaguan was opened at the end of the 1890 s, new commercial area and port area began to be built in the northwest of Nanjing. During the "Nanjing decade" from 1927 to 1937, the backbone of a new street system was built, starting from Xiaguan port, passing Xinjiekou area and leading to the east. New constructions took place along these roads. Starting from 1949, constructions extended further to the east and north of the city, taking use of the vacant land inside the city wall. The old city was largely replete before 1978, except some areas on the fringe. Then in 1992, new constructions were almost finished. After that the city experienced massive reconstruction mainly due to the real estate developments, while previous reconstructions to the built-up area just happened in a piecemeal way.
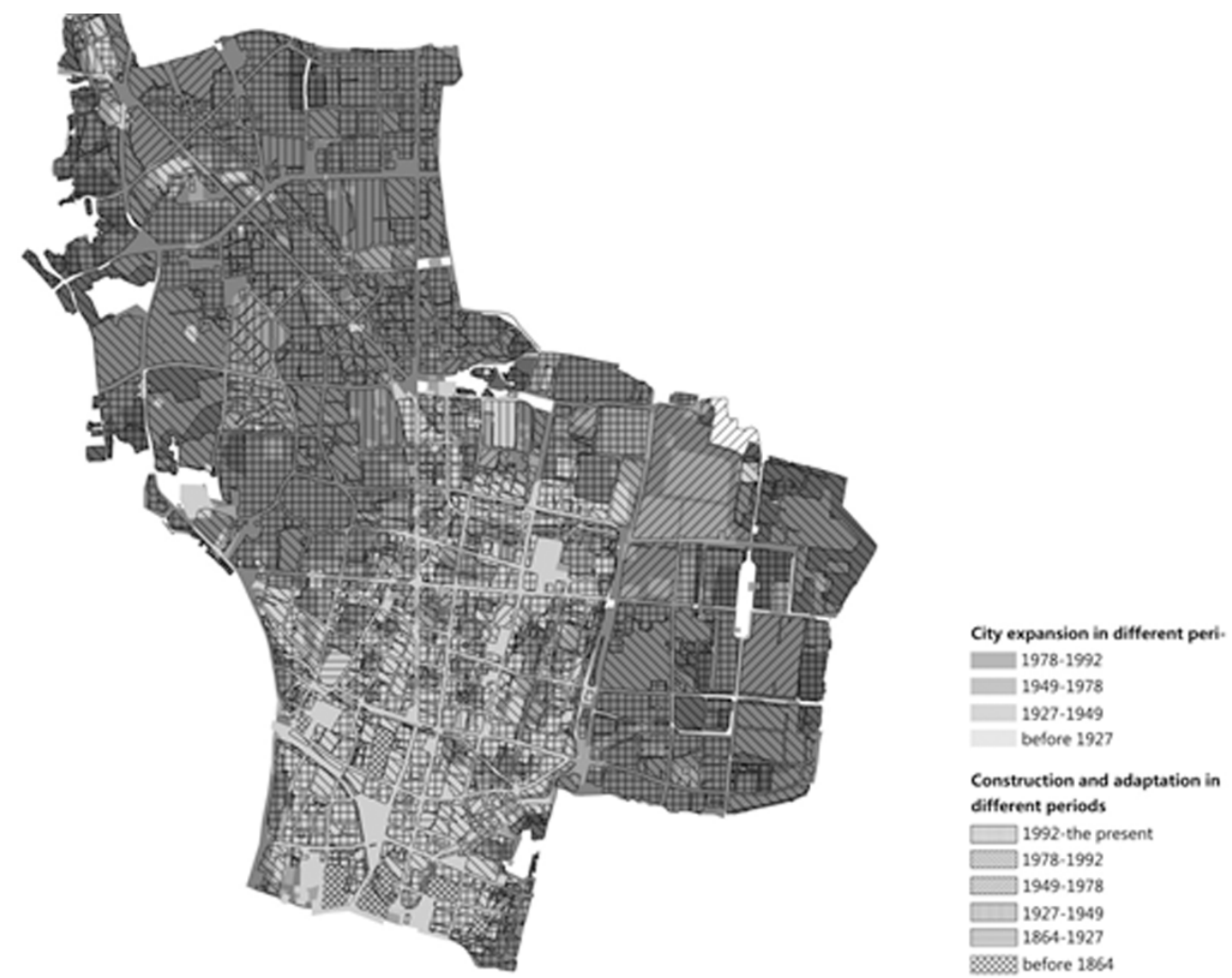

Figure 1. City expansion compared with construction and adaptation in each morphological period 
In this paper, plan units are delimited by the morphological periods in which the main streets and buildings of an urban area were constructed or adapted. Therefore, the current city could be firstly divided into five parts, numbered I, II, III, IV and V, and the corresponding construction periods are respectively 18641927, 1927-1949, 1949-1978, 1978-1992 and 1992-the present. Thus the plan units has been delimited theoretically, although the morphological differences between these units need to be further analyzed.

Apart from the morphological period, the morphological characters of an urban area are also influenced by the land utilization. Conzen pointed out the indirect contribution of land use pattern to the intermediate ranks of regionalization of Ludlow, through its individual elements adhering to the plot pattern and its broad land use zones. (Conzen, 1988) It was also demonstrated that the land utilization is subject to so many changes in history that it essentially represents the urban form of the recent period. This paper adopts the present land use classification in the city planning of Nanjing to do the second-order delimitation of landscape units. The Urban Land Use Classification and Standard for Development Land Planning (GB50137-2011) divides urban development land into eight patterns: residential area $(\mathrm{R})$; administration and public services area (A); commercial and business facilities area (B); industrial area (M); logistics and warehouse area (W); road, street and transportation area (S); municipal utilities area $(\mathrm{U})$; green space and square $(\mathrm{G})$. Since the aim of this paper is to study the morphological characters of blocks, only the intensive construction areas of the old city has been observed. Those areas mainly include four categories, namely, residential areas (R), administration and public services areas (A), commercial and business facilities areas (B) and industrial areas (M).

Then the plan units could be subdivided by these four land utilization categories with the help of GIS spatial analysis tools. The summary of the urban landscape units are listed as following:
I-R: residential areas (before 1864)

II-A: administration and public services areas (1864-1927)

III-R: residential areas (1927-1949)

III-M: industrial areas (1927-1949)

III-A: administration and public services areas (1927-1949)

IV-R: residential areas (1949-1978)

IV-M: industrial areas (1949-1978)

IV-B: commercial and business facilities areas (1949-1978)

IV-A: administration and public services areas (1949-1978)

V-R: residential areas (1978-1992)

V-M: industrial areas (1978-1992)

V-B: commercial and business facilities areas (1978-1992)

V-A: administration and public services areas (1978-1992)

VI-R: residential areas (1992-the present)

VI-M: industrial areas (1992-the present)

VI-B: commercial and business facilities areas (1992-the present)

VI-A: administration and public services areas (1992-the present)

\section{Morphological characters and types of urban blocks}

Block has been defined by American Planning Association as an area of land bounded by a street, or by a combination of streets and public parks, cemeteries, railroad rights-of-way, exterior boundaries of a subdivision, shorelines of waterways, or corporate boundaries. At many times a block is surrounded by streets, but it is unclear what kinds of street should be regarded as the boundary of city blocks. In China, there is a hierarchy of streets constituting the whole urban street system: expressways, primary streets, secondary streets and local streets. Main streets including expressways, primary streets and secondary streets are effectively controlled by city planning while many local streets may form spontaneously and lack later regulation. The idea of "superblocks", proposed by John Peponis, refers to the areas defined by a higher order network of major streets or thoroughfares. (John, 2015) Those main streets define an explicit grid of superblocks, which are subdivided into smaller blocks by the minor 
streets inserted. This idea provides a new view for the research of this paper that dual scales of blocks should be considered in response to the hierarchy street system. Rivers and green lands with notable barrier function are also taken as boundaries of adjacent blocks. Thus the intensive construction areas are divided into 76 superblocks, while large green areas or other open space are excluded.

It is obvious that the boundaries of urban landscape units intersect the boundaries of blocks mainly consisting of the street network. (Figure 2) That is different from the situation described by Meta Berghauser Pont and Per Haupt that the urban fabric consists of a collection of islands with homogeneous form, as well as the network that surrounds these islands and is required as access to the islands. (Berghauser Pont and Haupt, 2009) As a result, the area within one block may actually include parts of different form units and one urban fabric is usually separated by the street network. To better understand the distribution and aggregation regulation of urban fabric, the following part is focused on the relationship between superblocks and landscape units.

Considering the plan units contained, which are distinguished by construction periods, most superblocks could be divided into the following categories according to the primary morphological periods: early modern period, Nationalist government period, planned-economy period, early reform period and market-economy period. But some superblocks cannot be simply classified because they contain different plan units of the equivalent area. In the present plan of the old city, most superblocks have been reconstructed in part or whole from the year of 1992 to the present, except several blocks on the fringe. The reconstruction areas tend to be irregularly distributed within one superblock. (Figure 3)

In accordance with the dominant land use unit contained, the superblocks could be categorized into residential blocks, administration and public services blocks, commercial and business facilities blocks and industrial blocks. The only industrial block (No. 51) is under transformation so there is actually no large-scale industrial area inside the old city. Superblock No. 47 is the only one block completely occupied by commercial and business facilities. At many times commercial areas locate on the edge of superblocks, along the main streets. Therefore, the two main categories are mixed residential blocks and mixed administration and public service blocks. (Figure 4)

After mapping the urban landscape units, which is the combination of plan units and land use units, morphological configuration patterns of superblocks could be concluded. There are mainly two prototypes of superblocks, although in fact many superblocks are complex and may have the features of both prototypes. One type of superblock is evenly occupied by several large landscape units, such as the No. 30 superblock. This superblock is composed of residential areas in the west and northeast, constructed mainly in the $1990 \mathrm{~s}$, and gated work units in the middle and southeast, formed in the early 1950s and reconstructed in the 1980s and 1990s. Another type of superblock is dominated by one kind of fabric with some little heterogeneous units mixed in it. Those little heterogeneous units mainly including commercial and business facilities areas and administration and public service areas are usually distributed along the main streets and thus form a ring-shaped area surrounding the interior area. The No. 38 superblock is one example of this type, with several gated residential communities in the middle and groups of centralized commercial and business buildings on the edge. However, in the "Laochengnan" area, which is in the very south of the old city, many public facilities tend to be located along Qinhuai River. Those landscape units form a ribbon-shaped area crossing the superblocks. For instance, the superblock No. 75 is one superblock with Qinhuai River going through. It contains a large swath of traditional residential areas on both sides of the river and two narrow strips of land with small-scaled commercial buildings along the river. (Figure 5) In ancient times, this part of Qinhuai River had a lot of traffic so many commercial or cultural buildings were built beside it. Now the river has lost its transport functions, being a landscape element inside the superblocks, but the land use layout has remained. 

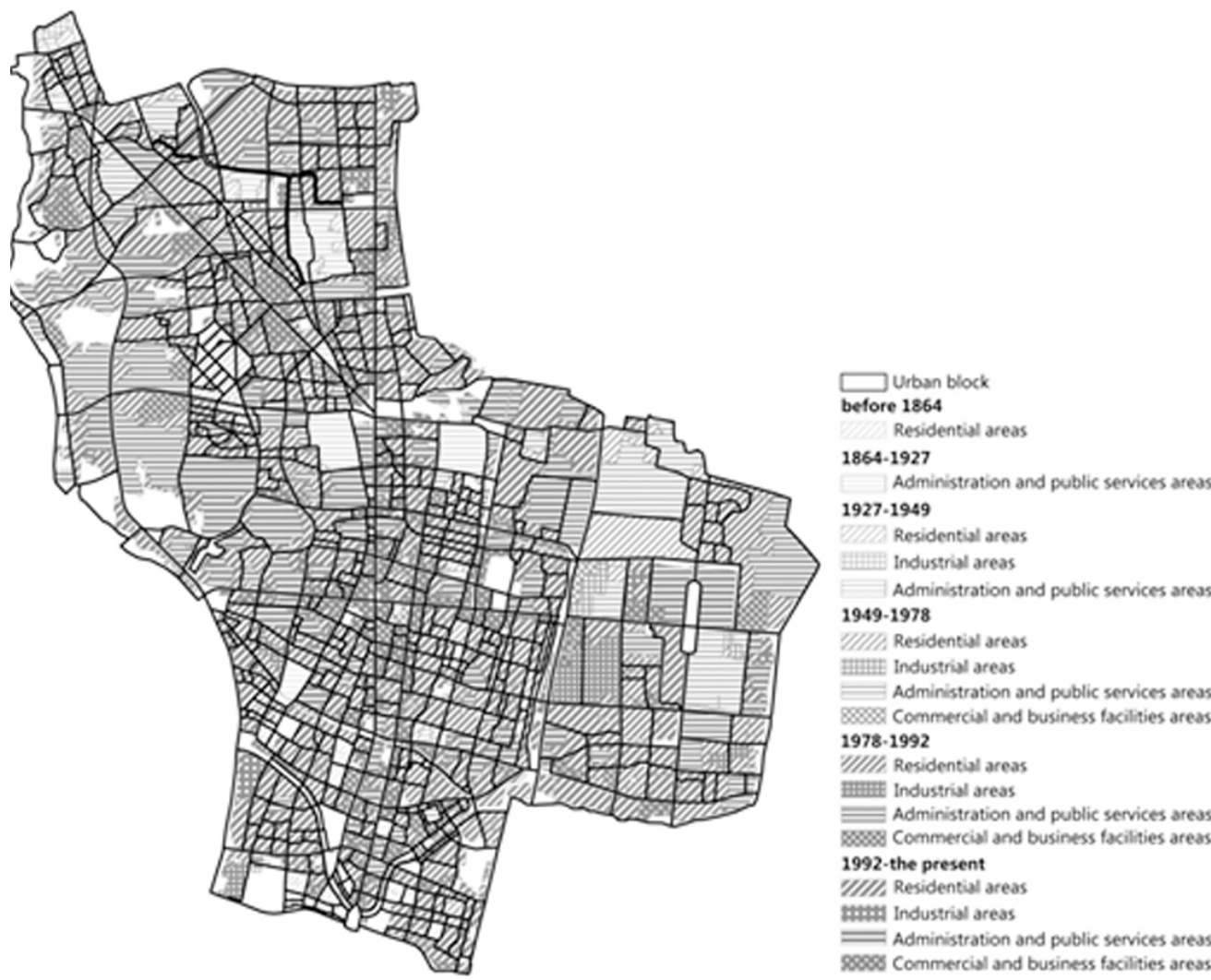

Figure 2. Urban landscape units and urban blocks

\section{Conclusion}

In this paper, the relationship between urban landscape units and city blocks of two different scales has been studied, in order to present and analyze the form of blocks in an intuitive way. City block is one of the basic elements of city planning and management, connected with the city structure at the macro level and also with buildings at the micro level. It is very important to understand the morphological characters of blocks in the present urban environment. The research has been conducted in the old city of Nanjing, where the city transformation in history has made the landscape with great complexity.

Based on the townscape research method mainly established by Conzen, the intensive construction area within the old city of Nanjing has been divided into 16 kinds of major landscape units. The division of landscape units is a comprehensive classification of homogeneous urban area in terms of ground plan and land utilization. The comparative study on the landscape units and the grid of city blocks has revealed that the boundaries of landscape unit usually deviate from the network of streets. The idea of "superblock" has been introduced to study the regulations of distribution and aggregation of urban fabrics. Considering the land utilization, most superblocks are mixed residential blocks or mixed administration and public service blocks. Finally, two configuration prototypes of superblocks have been found and the simplified diagrams could help us understand the complex form of city blocks.

This paper is a basic research on the block forms in the old city of Nanjing, as an addition to the existing intermediate-level morphological researches in China. Although studies on the specific morphology of landscape units and quantitative analyses on different types of blocks are likely to continue to be meaningful contents of the follow-up research, this research has not only offered a reference for the interpretation and description of urban blocks, but also established a foundation for the method exploration of urban development in China. 


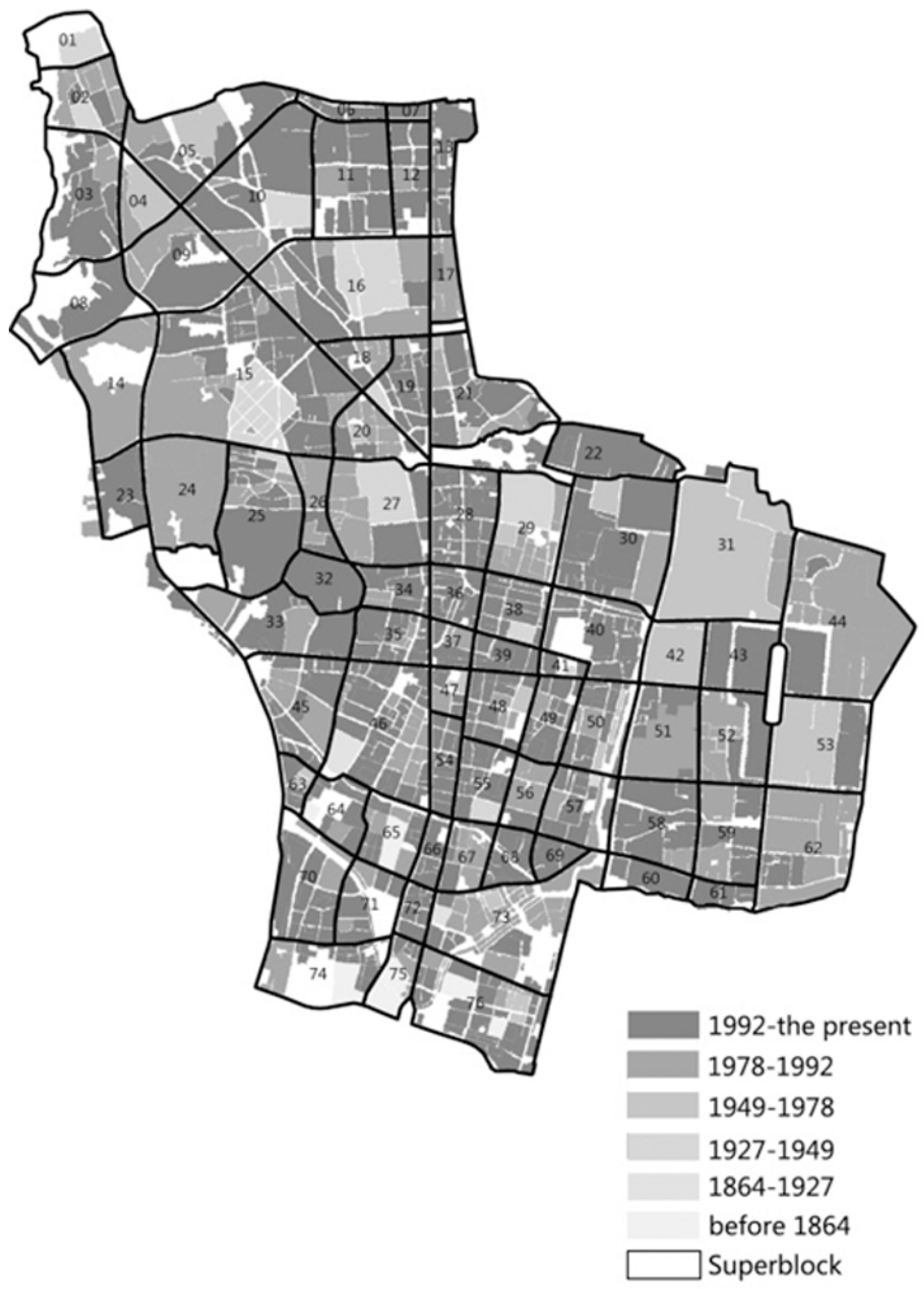

Figure 3. Plan units of different construction periods and superblocks 


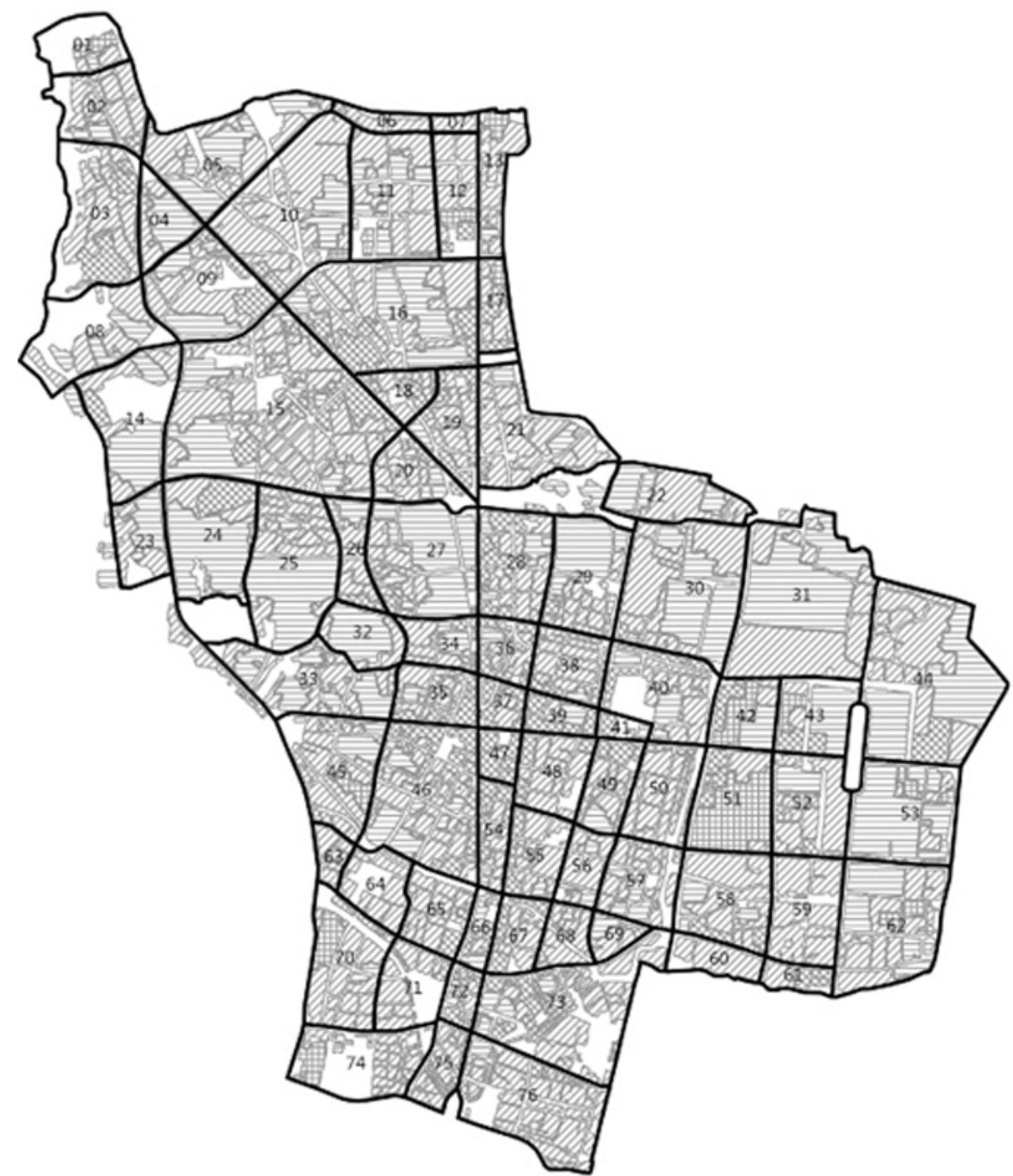

Administration and public services areas Industrial areas

Residential areas

Commercial and business facilities areas Superblock

Figure 4. Land use units and superblocks 

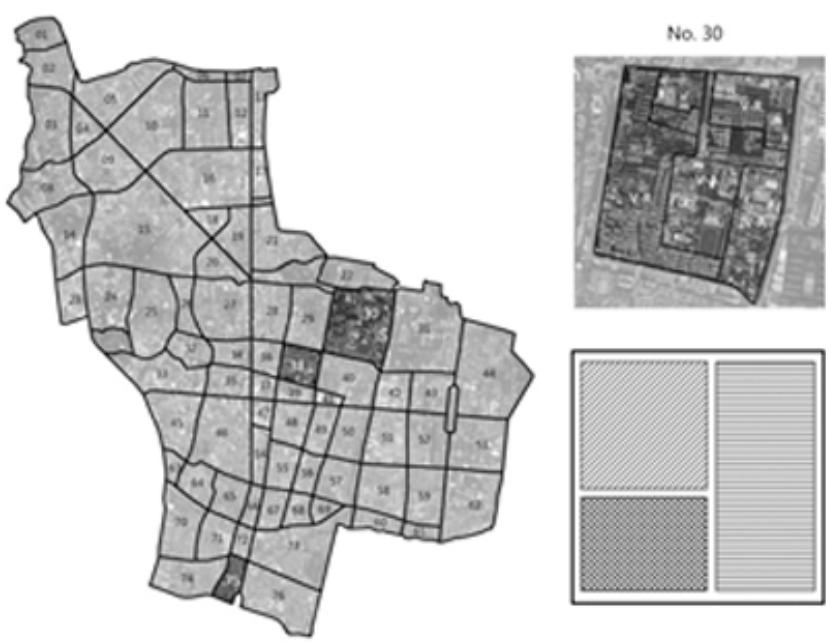

1 Superblock with juxtaposed units
No. 38
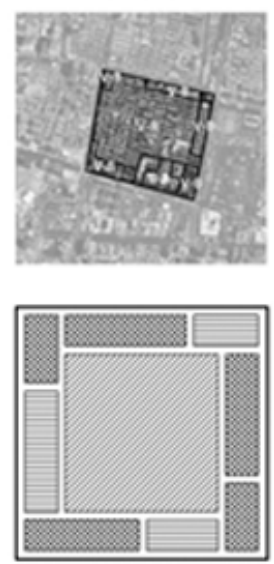

2.1 Superblock with heteroge: neous units in a ring
No. 75
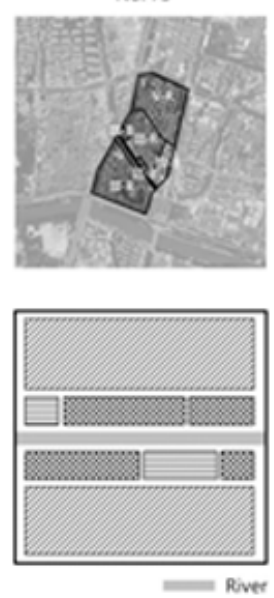

2-2 Superblock with heteroge. neous units in a nibbon

Figure 5. Prototypes of superblocks

\section{References}

Karl, K. (2014) 'Ambiguity in the definition of built form', Urban Morphology 18, 41-57.

Conzen, M. R. G. (1960) Alnwick, Northumberland: a study in town-plan analysis (Institute of British Geographers, London).

Lei, J. (2016) 'Morphological research of the historical urban boundary the inner fringe belt of Nanjing', unpublished $\mathrm{PhD}$ thesis, Politecnico di Torino, Torino.

Food and Agriculture Organization of the United Nations, F. (2004) 'Multilingual thesaurus on tenure', Chinese version, $32-$ 33.

Yi, W. (2016) 'Chengshi shehui kongjian de lishitai yanbian ji dongli jizhi (Historic evolution of city social space and motivation mechanism)', Shanghai Urban Management 25, 66-70.

Whitehand, J. (2009) 'The structure of urban landscapes: strengthening research and practice', Urban Morphology 13, 5-27.

Jiang, L. and Hui, S. (2007) Pattern and Mechanism: the Urban Transformation of the City Centers in China (China Architecture and Building Press, Beijing). 